\title{
Distal respiratory tract viral infections in young children trigger a marked increase in alveolar mast cells
}

\author{
Cecilia K. Andersson ${ }^{1,2}$, Medya Shikhagaie ${ }^{2}$, Michiko Mori ${ }^{2}$, Amal Al-Garawi ${ }^{3}$, \\ Jennifer L. Reed ${ }^{4}$, Alison A. Humbles ${ }^{5}$, Robert Welliver ${ }^{6}$, Thais Mauad ${ }^{7}$, \\ Leif Bjermer ${ }^{1}$, Manel Jordana ${ }^{3}$ and Jonas S. Erjefält ${ }^{2}$
}

Affiliations: 'Dept of Respiratory Medicine and Allergology, Lund University, Lund, Sweden. ${ }^{2}$ Unit of Airway Inflammation, Lund University, Lund, Sweden. ${ }^{3}$ McMaster Immunology Research Centre, McMaster University, Hamilton, ON, Canada. 'Laboratory of Plasma Derivatives, Center for Biologics Evaluation and Research, Food and Drug Administration, Rockville, MD, USA. ${ }^{5}$ Dept of Respiratory, Inflammation, and Autoimmunity, Medlmmune LLC, Gaithersburg, MD, USA. ${ }^{6}$ Dept of Pediatrics, University of Oklahoma University Health Sciences Center, Oklahoma City, OK, USA. ${ }^{7}$ Dept of Pathology, São Paulo University, São Paulo, Brazil.

Correspondence: Cecilia K. Andersson, Unit of Airway Inflammation, Respiratory Medicine and Allergology, Dept of Clinical Sciences, BMC D12, Lund University, SE-22184, Lund, Sweden.

E-mail: cecilia.anderssonamed.lu.se

ABSTRACT Viral infections predispose to the development of childhood asthma, a disease associated with increased lung mast cells (MCs). This study investigated whether viral lower respiratory tract infections (LRTIs) can already evoke a MC response during childhood.

Lung tissue from young children who died following LRTIs were processed for immunohistochemical identification of MCs. Children who died from nonrespiratory causes served as controls. MCs were examined in relation to sensitisation in infant mice exposed to allergen during influenza A infection.

Increased numbers of MCs were observed in the alveolar parenchyma of children infected with LRTIs (median (range) $12.5(0-78)$ MCs per $\mathrm{mm}^{2}$ ) compared to controls (0.63 (0-4) MCs per $\left.\mathrm{mm}^{2}, \mathrm{p}=0.0005\right)$. The alveolar MC expansion was associated with a higher proportion of $\mathrm{CD}_{3} 4^{+}$tryptase $^{+}$progenitors (controls: $0 \%(0-1 \%)$; LRTIs: $\left.0.9 \%(0-3 \%) \mathrm{CD}_{3} 4^{+} \mathrm{MCs}(\mathrm{p}=0.01)\right)$ and an increased expression of the vascular cell adhesion molecule (VCAM)-1 (controls: 0.2 (0.07-0.3); LRTIs: 0.3 (0.02-2) VCAM-1 per $\left.\mathrm{mm}^{2}(\mathrm{p}=0.04)\right)$. Similarly, infant mice infected with H1N1 alone or together with house dust mite (HDM) developed an increase in alveolar MCs (saline: 0.4 (0.3-0.5); HDM: 0.6 (0.4-0.9); H1N1: 1.4 (0.4-2.0); HDM+H1N1: $2.2(1.2-4.4)$ MCs per $\left.\mathrm{mm}^{2}(\mathrm{p}<0.0001)\right)$. Alveolar MCs continued to increase and remained significantly higher into adulthood when exposed to H1N1+HDM (day 36: 2.2 (1.2-4.4); day 57: 4.6 (1.6-15) MCs per $\left.\mathrm{mm}^{2}(\mathrm{p}=0.01)\right)$ but not when infected with H1N1 alone.

Our data demonstrate that distal viral infections in young children evoke a rapid accumulation of alveolar MCs. Apart from revealing a novel immune response to distal infections, our data may have important implications for the link between viral infections during early childhood and subsequent asthma development.

@ERSpublications

Viral infections in children evokes a rapid recruitment and accumulation of mast cells in the alveolar parenchyma http://ow.ly/i9eN30meNM7

Cite this article as: Andersson CK, Shikhagaie M, Mori M, et al. Distal respiratory tract viral infections in young children trigger a marked increase in alveolar mast cells. ERJ Open Res 2018; 4: 00038-2018 [https://doi.org/10.1183/23120541.00038-2018].

This article has supplementary material available from openres.ersjournals.com

Received: March 072018 | Accepted after revision: Oct 052018

The content of this work is copyright of the authors or their employers. Design and branding are copyright @ERS 2018. This version is distributed under the terms of the Creative Commons Attribution Non-Commercial Licence 4.0. 


\section{Introduction}

Lower respiratory tract infections (LRTIs) are associated with a substantial disease burden in young children. Influenza A, respiratory syncytial virus (RSV) and adenovirus (ADV) are major causes of LRTIs including bronchiolitis, croup and pneumonia in infants [1]. Studies on the frequency of viral infections in developed countries have shown that infants and preschool children experience 6-10 viral infections annually [2]. The risk of developing asthma is increased with frequent viral-induced bronchiolitic episodes in combination with allergic sensitisation to airborne allergens [3, 4]. Albeit that there is strong evidence from longitudinal studies, it is not known how distal viral infections during early childhood are connected to the development of asthma $[5,6]$.

Previous studies have revealed a surprisingly high density of alveolar mast cells (MCs) in healthy adult lungs [7]. The presence of large numbers of MCs at mucosal surfaces such as the lung suggests that these cells may play a crucial role in the innate immune defence against pathogens, toxins and tissue damage [8]. Indeed, studies in animal models have shown increased mortality after infections in MC-deficient mice $[9,10]$. In addition, increased numbers of bronchiolar MCs have been reported in an animal model of viral bronchiolitis and this increase was associated with hyperresponsiveness to methacholine [11]. However, almost nothing is known regarding the MC responses to viral infection in human lungs, especially in the alveolar parenchyma, where both human and animal data are lacking.

Although asthma has classically been considered a disease of the central airways, new data suggest that both bronchioles and the alveolar parenchyma are subjected to inflammation [12-18]. Interestingly, among the most marked alveolar changes in asthma is an expanded and activated pool of alveolar MCs $[18,19]$. Whether a similar MC response occurs during LRTIs as well as the potential link between LRTIs and distal MC responses in asthma, remains unknown.

Here, we have studied the recruitment and heterogeneity of MCs in a unique lung tissue material from children who suffered from fatal LRTIs. Furthermore, the connection to allergic sensitisation and the development of an asthmatic phenotype was studied in a mouse model of influenza A infection and house dust mite (HDM) exposure in infant mice.

\section{Material and methods}

Model of influenza A infection and allergic inflammation in infant mice

15-day pregnant (female) BALB/c mice were purchased from Charles River Laboratories (Ottawa, ON, Canada), housed under specific pathogen-free conditions, and maintained on a 12-h light-dark cycle with food and water ad libitum. Upon birth, mothers were housed with their litters in light-protected cages until completion of the study (or weaning at 4 weeks of age). 8-day-old mice were infected with influenza A and, 7 days later, exposed to HDM 5 days a week for a total of 3 weeks. To investigate whether changes persisted, the protocol was recapitulated and mice were allowed to rest for a period of 3 weeks. Animals were monitored for signs of illness twice daily for a period of 10 days following infection. To evaluate the total number of MCs, 3- $\mu \mathrm{m}$ sections were prepared and the sections were stained with a $1 \%$ solution of toluidine blue. Thereafter, MCs per section were counted and related to tissue area using ImageScope (Aperio, Vista, CA, USA). All experiments described in this study were approved by the Animal Research Ethics Board of McMaster University (Hamilton, ON, Canada). For details, see the supplementary material.

\section{Subjects}

Lung samples from post mortem lung tissue from young children (median age (range): 4 (5-16) months) who died from fatal LRTIs was collected (RSV, $n=5 ; A D V, n=10$; and influenza $A, n=6$ ). Control lung tissues were obtained from 10 age-matched children $(3(0.4-24)$ months) who died from nonrespiratory causes. All tissue samples were collected with informed parental consent. This study was approved by the institutional medical ethical committee, Sao Paulo, Brazil, and at the Institute of Legal Medicine of the Medical School of the Hanover University, Hanover, Germany. For details, see the supplementary material.

\section{Immunohistochemistry}

Double immunohistochemical staining of MCTC and MCT

A double staining protocol was used for simultaneous visualisation of MCTC and MCT cells [7, 18, 20]. The staining was performed on paraformaldehyde-fixed, paraffin-embedded tissue by an automated immunohistochemistry robot. For details, see table 1 and the supplementary material. 


\begin{tabular}{|c|c|c|c|c|c|}
\hline Antibody & Species & Dilution & Clone & Origin & Secondary antibody \\
\hline Tryptase & Mouse & $1: 12000$ & G3 & $\begin{array}{c}\text { Chemicon, (Temecula, } \\
\text { CA, USA) }\end{array}$ & $\begin{array}{c}\text { EnVision G|2 Doublestain } \\
\text { System directly labelled with Alexa } \\
\text { Fluor } 488\end{array}$ \\
\hline Chymase & Mouse & $1: 100$ & $\mathrm{CC} 1$ & $\begin{array}{c}\text { Novocastra (Newcastle } \\
\text { upon Tyne, UK) }\end{array}$ & $\begin{array}{l}\text { EnVision G|2 Doublestain System } \\
\text { (Dako, Glostrup, Denmark) }\end{array}$ \\
\hline CD34 & Mouse & $1: 300$ & $\begin{array}{c}\text { QBEnd/ } \\
10\end{array}$ & $\begin{array}{l}\text { Dako, (Glostrup, } \\
\text { Denmark) }\end{array}$ & Invitrogen (Eugene, OR, USA) \\
\hline VCAM-1 & Mouse & $1: 100$ & $1.4 \mathrm{C} 3$ & $\begin{array}{c}\text { Invitrogen Molecular } \\
\text { Probes (Eugene, OR, } \\
\text { USA) }\end{array}$ & EnVision Detection system, Dako \\
\hline Ki-67 & Rabbit & 1:100 & & $\begin{array}{c}\text { Biocare (Pacheco, CA, } \\
\text { USA) }\end{array}$ & Invitrogen (Eugene, OR, USA) \\
\hline ITGA4 & Rabbit & $1: 50$ & & $\begin{array}{l}\text { LifeSpan Biosciences } \\
\text { (Seattle, WA, USA) }\end{array}$ & Invitrogen (Eugene, OR, USA) \\
\hline ITGB1 & Rabbit & $1: 50$ & & $\begin{array}{l}\text { LifeSpan Biosciences } \\
\text { (Seattle, WA, USA) }\end{array}$ & Invitrogen (Eugene, OR, USA) \\
\hline
\end{tabular}

Heat-induced antigen retrieval was performed in PT link (Dako, Glostrup, Denmark) with EnVision FLEX Target retrieval solution high $\mathrm{pH}$ (Dako). VCAM: vascular cell adhesion molecule; ITGA4: integrin $\alpha_{4}$; ITGB1: integrin $\beta_{1}$.

Immunohistochemical identification of VCAM-1 and CD34, ITGB1/A4 and Ki-67+ MCs

Immunofluorescence double staining was used to visualise expression of CD34, integrin $\beta_{1}$ (ITGB1), integrin $\alpha_{4}$ (ITGA4) or Ki-67 on tryptase-positive MCs. A single staining protocol was used for visualisation of VCAM-1. For details, see table 1 and the supplementary material.

\section{Tissue analysis}

\section{Quantification of density of MC subtypes}

High-resolution digital images of sections double-stained for МСTC and МCT were generated through a $20 \times$ microscope lens by an automated digital slide-scanning robot (Scanscope CS; Aperio). All MCs were quantified manually on blinded sections and related to the perimeter of the basal membrane (small airways and pulmonary vessels) or tissue area (alveolar parenchyma) using Visiomorph (Visiopharm, Hoersholm, Denmark) [18]. For details, see the supplementary material.

Quantification of VCAM-1 and CD34, ITGB1, ITGA4 and Ki-67+ MCS

The immunoreactivity per square millimetre of tissue area of VCAM-1 was calculated using Visiomorph. Tryptase-positive MCs and expression of CD34, ITGB1, ITGA4 and Ki-67 was analysed and the proportion (\%) of positive MCs was calculated. For details, see the supplementary material.

\section{Statistical analysis}

Data were analysed using Kruskal-Wallis test with Dunn's multiple comparisons test for comparison among three groups or more and Mann-Whitney rank sum test was used for comparison between two groups using GraphPad Prism version 5 (GraphPad Software, Inc., La Jolla, CA, USA). The Spearman test (two-tailed) was used to study the correlations. Correlation analysis was made within pooled LRTI-infected children. Results were considered significant at $\mathrm{p} \leqslant 0.05$.

\section{Results}

Increased number of MCs in a model of allergic inflammation during the course of an influenza $A$ infection in infant mice

To address whether LRTIs directly contribute to increased pulmonary abundance of MCs in the context of allergic asthma, we investigated MCs in mice infected post-natally (8 days old) with influenza A (H1N1) and or challenged with HDM (figure $1 \mathrm{a}$ and $\mathrm{b}$ ). The number of MCs, defined as purple toluidine blue-positive granulated cells [21], were quantified in the alveolar parenchyma of control mice and mice infected with influenza A, exposed to HDM, or both infected with influenza A and exposed to HDM, and normalised for tissue area. Only low numbers of MCs were detected in the lungs of saline- or HDM-treated infant mice (figure $1 \mathrm{c}, \mathrm{f}$ and $\mathrm{g}$ ). At day $36, \mathrm{MCs}$ were increased in infant mice infected with influenza A and, even more so, in mice infected with influenza A with concomitant HDM exposure 
a) H1N1 (or PBS) HDM (or PBS)

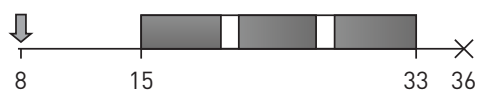

b) H1N1 (or PBS) HDM (or PBS)

\begin{tabular}{ccc|c|ccc}
\cline { 2 - 5 } & & & & No HDM & $\times$ \\
8 & 15 & $\begin{array}{c}2 \text { days } \\
\text { rest } \\
\text { Age days }\end{array}$ & 33 & & 57 \\
& \multicolumn{3}{c}{ Age das } &
\end{tabular}
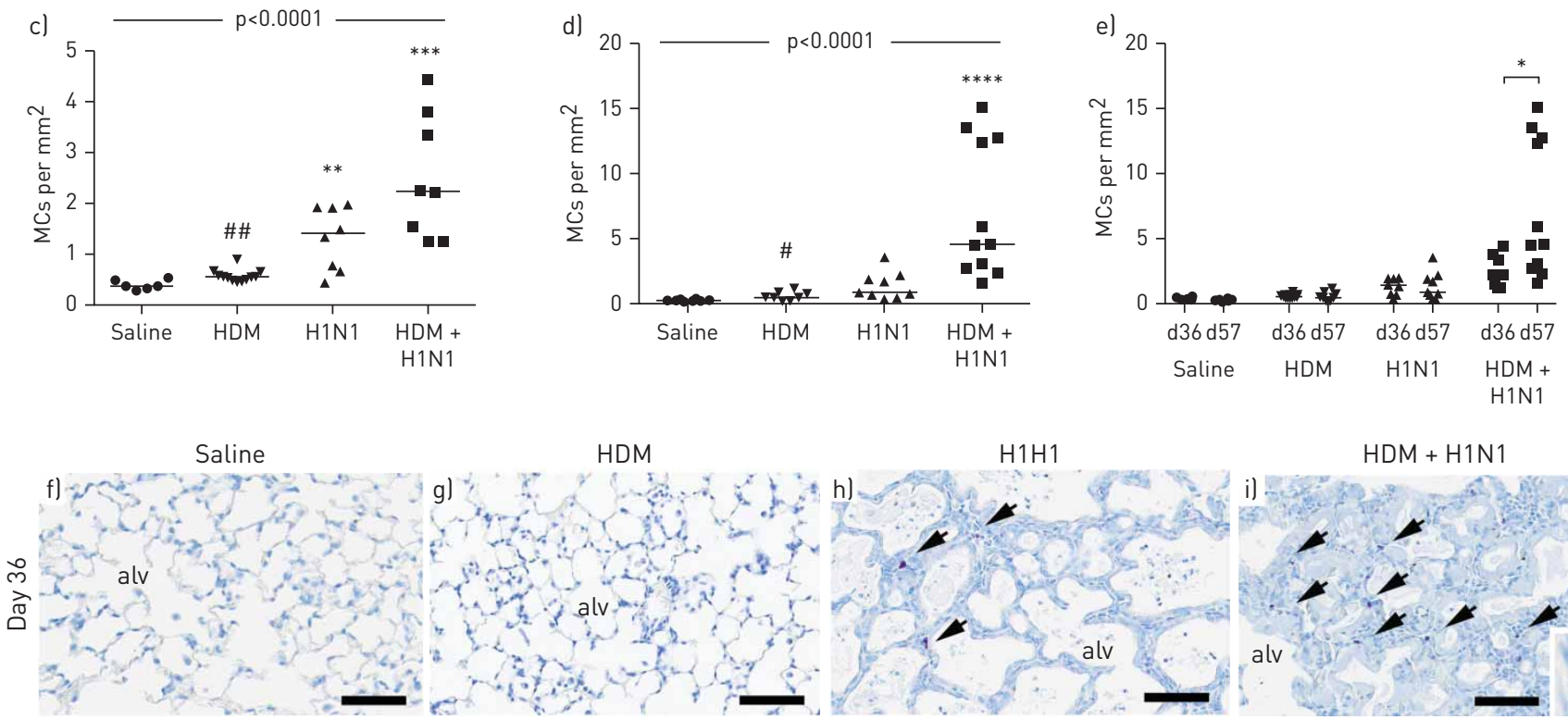

$\mathrm{HDM}+\mathrm{H} 1 \mathrm{~N} 1$
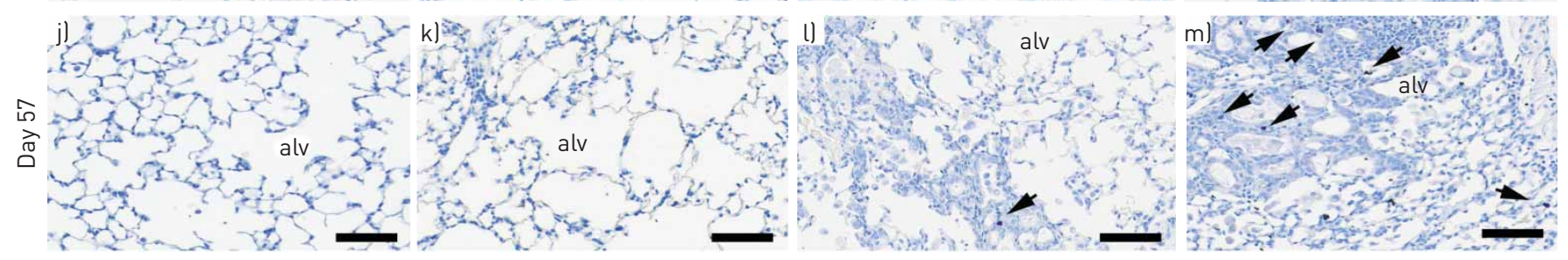

FIGURE 1 Experimental plan. a) 8-day-old mice were infected with influenza A virus (H1N1) or given PBS alone. 7 days later, PBS- and H1N1-infected groups were exposed either to 3 weeks of house dust mite (HDM) or saline and sacrificed $72 \mathrm{~h}$ after the last HDM exposure (day 36). b) Separate groups of 8-day-old mice were infected with influenza virus or given PBS alone. 7 days later, PBS- and H1N1-infected groups were exposed either to 3 weeks of HDM or saline, then, after the last HDM exposure, mice were rested for 3 weeks and sacrificed at 8 weeks of age (day 57). Mast cell (MC) densities in alveolar parenchyma in mice exposed to HDM or H1N1 alone or in combination compared to saline-treated animals: c) day 36 and d) day 57. e) MC densities at day 36 compared to day 57 in all groups. Toluidine blue stained slides (MCs shown in purple) picturing alveolar parenchyma from $\mathrm{f}$ and j) saline-, g and k) HDM-, h and () H1N1-, and i and m) HDM+H1N1-treated animals. Scale bars $=200 \mu \mathrm{m}$. Overall significance, using Kruskal-Wallis test, is denoted in each panel. Results were considered significant at $p \leqslant 0.05$, and individual differences between groups using Kruskal-Wallis test with Dunn's post hoc test. alv: alveolus. ${ }^{* *}: \mathrm{p} \leqslant 0.01$ versus controls; ${ }^{* * *}$ : $\mathrm{p} \leqslant 0.001$ versus controls; ${ }^{* * *}: \mathrm{p} \leqslant 0.0001$ versus controls; ${ }^{\#}: \mathrm{p} \leqslant 0.05$ between HDM+H1N1 and HDM; ${ }^{\# \#}$ : $\mathrm{p} \leqslant 0.01$ between HDM+H1N1 and HDM.

(figure $1 \mathrm{a}, \mathrm{b}, \mathrm{h}$ and i). When allowed further to recover for 3 weeks (day 57 of age), the MC numbers where only significantly increased in mice infected with influenza A and exposed to HDM (figure 1d and $\mathrm{m}$ ). Higher levels of MCs were observed in mice infected with influenza A and exposed to HDM at day 57 compared to day 36 (figure 1e). No increase in MC numbers was observed in mice exposed to HDM alone at day 36 or 57 compared to control animals (figure 1c, d, g and k). At both time points, MC numbers were significantly increased in HDM+influenza A compared to HDM alone (figure 1c and d).

Markedly elevated MC density in alveolar parenchyma in children who have died following LRTIs To further study the number of MCs under relevant human conditions, the density and anatomical localisation of distal lung MCs were quantified in the small airways (bronchioles), pulmonary vessels and the alveolar parenchyma in young children who died of LRTIs compared to controls. Interestingly, the control lungs virtually lacked alveolar mast cells (figure $2 \mathrm{c}$ and table 2), a result which contrasts the MC-rich alveolar parenchyma of adult healthy human lungs [7]. 

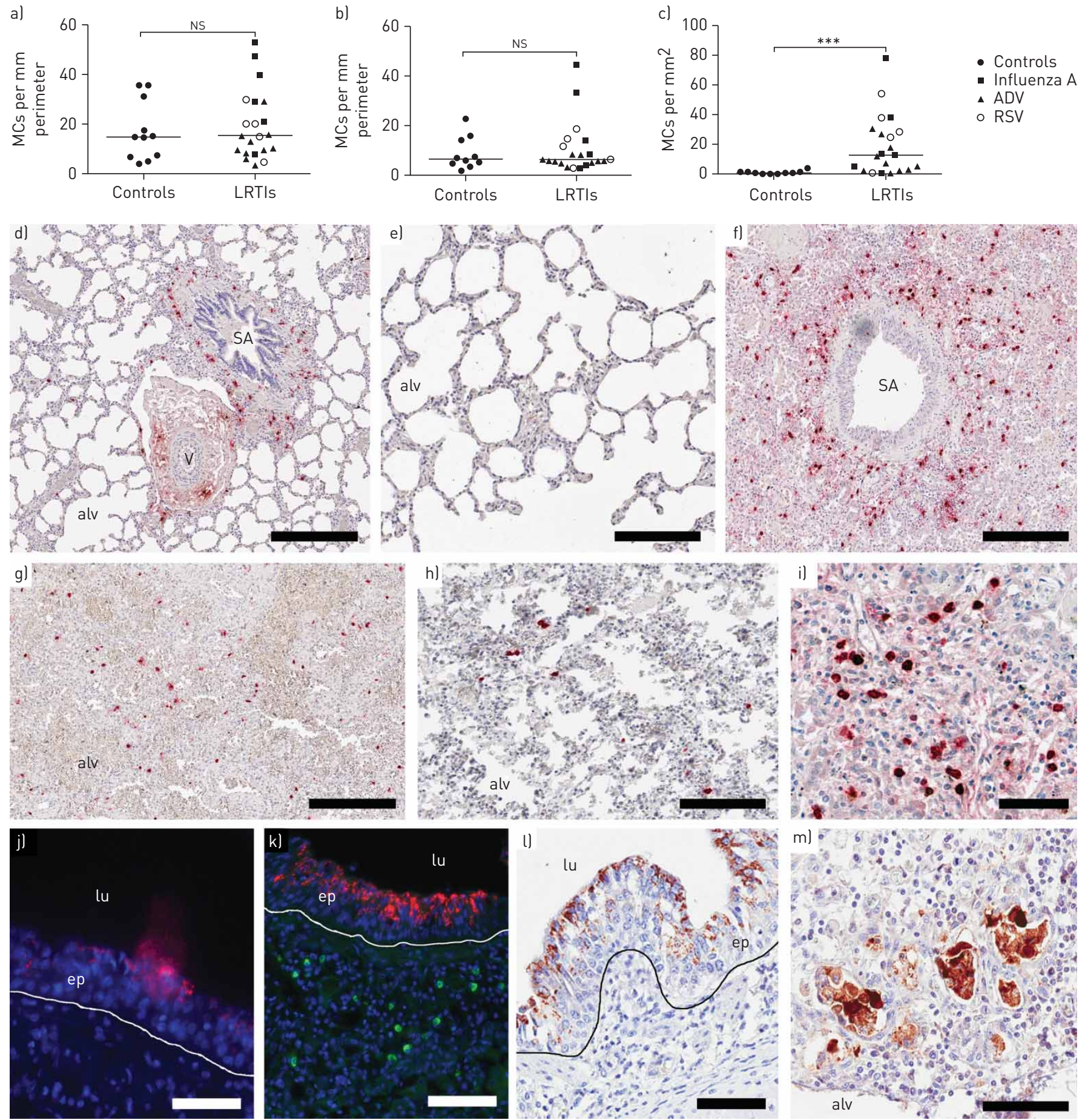

FIGURE 2 Mast cell (MC) densities in a) small airways, b) pulmonary vessels and c) alveolar parenchyma. Double immunohistochemical staining for tryptase (red) and chymase (brown). Representative photograph of d) a small airway and pulmonary vessel in a control lung from a child and e) alveolar parenchyma. f) Small airway in a lung from a child infected with influenza A. Alveolar parenchyma from young children who have died following g) respiratory syncytial virus (RSV), h) adenovirus (ADV) and i) influenza infections. Immunohistochemical staining for influenza A (red) in the epithelium with $\mathrm{j}$ and $\mathrm{k}$ ) fluorescence and () 3,3'-diaminobenzidine. $\mathrm{k}$ ) Tryptase-positive MCs are shown in the subepithelium (green). m) RSV positivity in the alveolar parenchyma. Scale bars: d, f and gl $500 \mu \mathrm{m}$; el $200 \mu \mathrm{m} ; \mathrm{h}$ and k) $100 \mu \mathrm{m}$; i and m) $70 \mu \mathrm{m} ; j$ and l) $50 \mu \mathrm{m}$. Results were considered significant at $p \leqslant 0.05$. NS: not significant; LRTI: lower respiratory tract infection; SA: small airway; V: vessel; alv: alveolus; lu: lumen; ep: epithelium. ${ }^{* * *}: p \leqslant 0.001$ using Mann-Whitney rank sum test, in comparison to controls.

The density of MCs in small airways or the pulmonary vessels was not statistically altered in LRTI-affected lungs compared to controls (figure $2 \mathrm{a}, \mathrm{b}, \mathrm{d}, \mathrm{f}, \mathrm{j}$ and $\mathrm{k}$ ). However, there was a marked and significant increase in MC numbers in the alveolar parenchyma in LRTIs (figure $2 c, e, g-i$ and $\mathrm{m}$ ). The increase was 
TABLE 2 Mast cell (MC) densities in young children with lower respiratory tract infections compared to controls

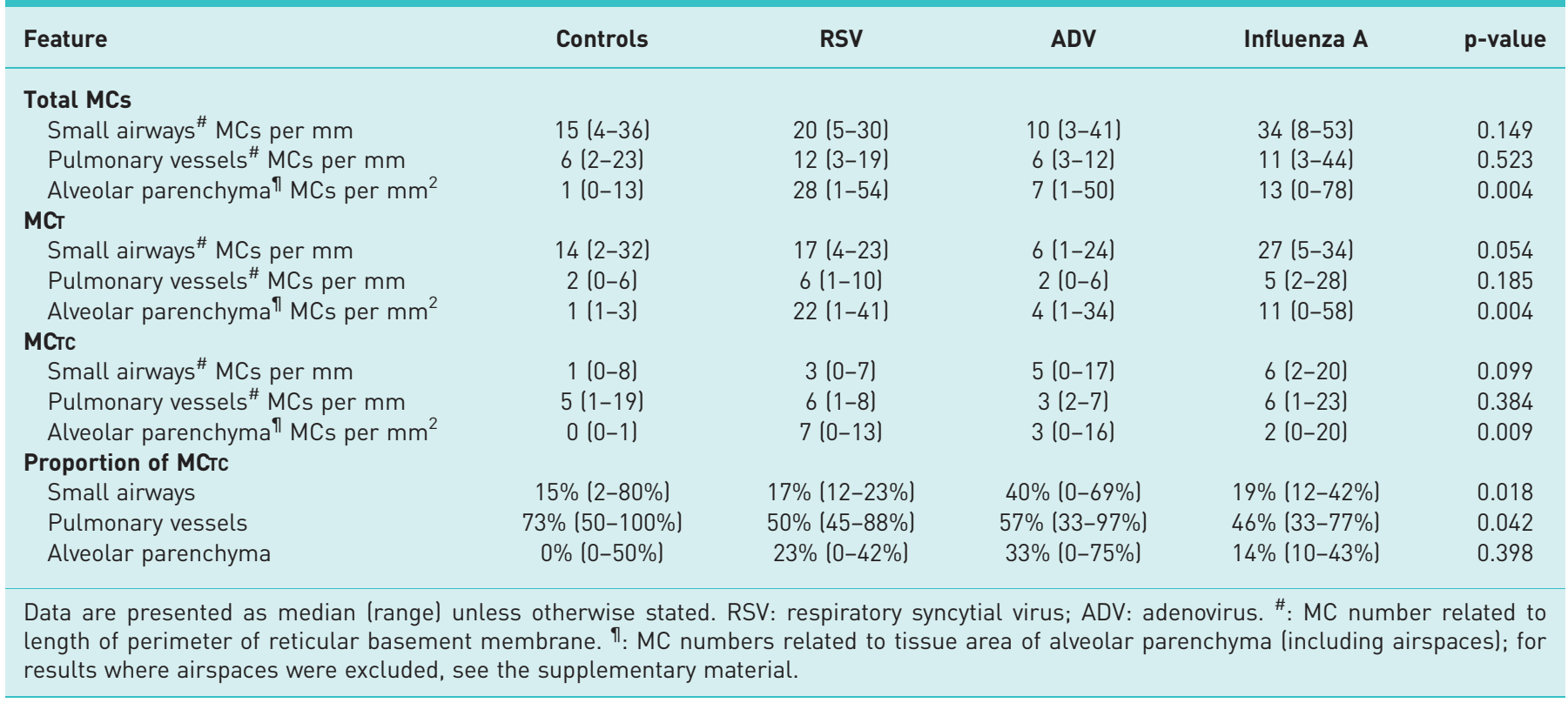

significant for both MCT and MCTC, subpopulations and present in RSV, ADV and influenza A infection. For details regarding different LRTIs and MC populations, see table 2.

Increased frequency of MC progenitors in the alveolar parenchyma after viral infections

The median time with symptoms before death in the infected children were only 4 days (range 1-8 days). Since the LRTI-induced expansion of the alveolar MC pool thus took place rapidly after infection, we postulated that this would be linked with elevated levels of parenchymal MC progenitors, defined here as tryptase $^{+}$MCs double positive for the hematopoietic marker CD34. In small airways and pulmonary vessels, the frequency of MC progenitors was not significantly altered in children with LRTIs (figure 3a and b). The alveolar parenchyma, the only pulmonary structure where an accumulation of MCs was observed, contained a significantly higher frequency of MC progenitors $(p<0.01)$ (figure $3 \mathrm{a})$. Next, it was confirmed that mast cells in LRTI-affected lungs did express adhesion molecules integrin $\alpha_{4} \beta_{1}$ that is thought to be critical for MC progenitor homing into tissue [22]. Although constituting a small proportion of all MCs, tryptase ${ }^{+}$integrin $\alpha 4 \beta 1^{+} \mathrm{MCs}$, phenotypically characterised as small and round, were clearly observed in the alveolar parenchyma of children who died following LRTIs (figure $3 \mathrm{f}-\mathrm{k}$ ).

\section{MCs do not proliferate locally in the lung of young children with LRTI}

We next analysed the proliferation of MCs, defined as tryptase ${ }^{+}$cells double positive for the proliferation marker Ki67. Scattered Ki-67 ${ }^{+}$cells were found throughout the lungs (figure $3 \mathrm{c}$ and d). Ki-67 immunoreactivity was not detected within tryptase ${ }^{+}$cells, suggesting that the increased MC density was not dependent on local proliferation. In agreement with this, proliferative MCs were not found in adult lungs from patients with chronic obstructive pulmonary disease (COPD) or cystic fibrosis (data not shown). However, $\sim 2 \%$ of the total MCs (tryptase ${ }^{+}$) were identified as proliferating by Ki-67 immunostaining in bronchial lymph nodes from patients with very severe COPD (data not shown).

Our group has previously shown that $\mathrm{FcERI}^{+}$alveolar MCs and IgE bound to alveolar MCs is a hallmark of atopic asthma in adults $[18,19]$. Immunofluorescence double staining revealed that lungs from both noninfected and LRTI-affected young children lacked MCs with surface-bound IgE (figure 3e). However, $\mathrm{IgE}^{+} \mathrm{CD}_{138^{+}}$plasma cells were found in close proximity to MCs in the lungs of children with LRTI (inset in figure $3 \mathrm{e}$ ).

\section{LRTI-affected lungs express elevated levels of the MC migration-facilitating molecule VCAM-1}

Tissue recruitment and homing of MCs occurs through a process of endothelial VCAM-1 binding of MC integrins [23]. To investigate whether MC accumulation among children with fatal LRTI is associated with an induction of endothelial VCAM-1, the immunoreactivity of VCAM-1 was measured and related to sequential slides where the MCs were quantified. No difference in VCAM-1 expression was observed in 


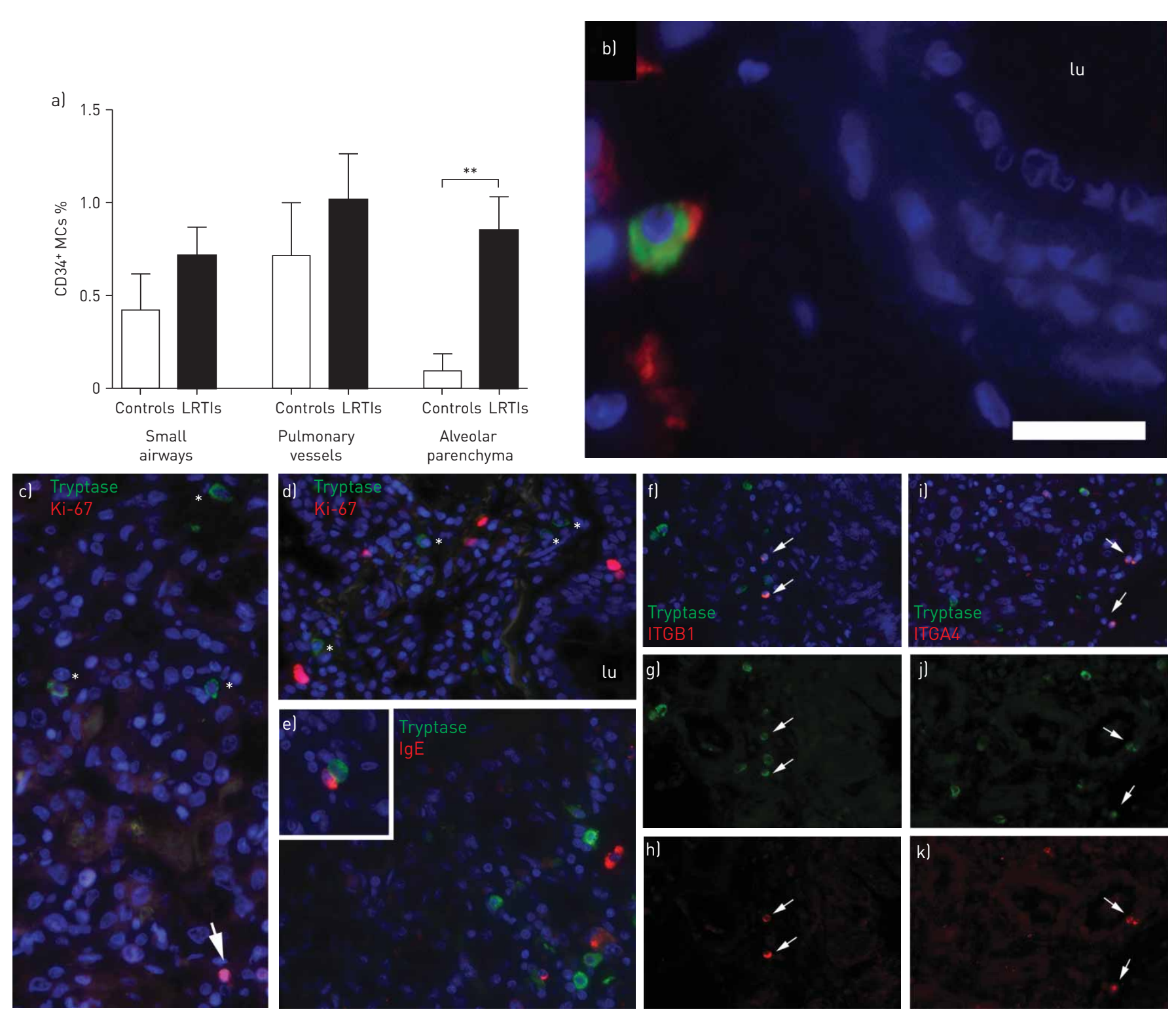

FIGURE 3 a) Proportion of CD34 ${ }^{+}$mast cells (MCs) in small airways, pulmonary vessels and alveolar parenchyma. b) CD34 (red) MCs (green) in a pulmonary vessel wall. Scale bar $=30 \mu \mathrm{m}$ ). c and d) Influenza A-infected lung stained for tryptase (green) and proliferation marker Ki-67 (red). Arrows show $\mathrm{Ki}-67^{+}$cells and ${ }^{*}$ denotes tryptase ${ }^{+}$cells. e) Alveolar parenchyma stained for tryptase (green) and IgE (red). Inset shows neighbouring $\operatorname{lgE}^{+}$cell and MC. f-h) Alveolar parenchyma stained for tryptase (green) and integrin $\beta_{1}$ (ITGB1) (red). i-k) Tryptase (green) integrin $\alpha_{4}$ (ITGA4) (red). Integrin ${ }^{+}$MCs are denoted with arrows. Results were considered significant at $p \leqslant 0.05$. lu: lumen. ${ }^{* *}: p \leqslant 0.01$ using Mann-Whitney rank sum test, in comparison to controls.

small airway walls (figure 4a). In pulmonary vessels, the VCAM-1 density decreased compared to controls (figure $4 \mathrm{~b}$ ). In contrast, an increased VCAM-1 expression was observed in the alveolar parenchyma in LRTI-affected lungs compared to controls (figure 4c).

\section{Discussion}

The results from our study demonstrate that a viral infection affecting the peripheral lung evokes a rapid accumulation of MCs in the alveolar parenchyma in both young children and mice. Apart from revealing a novel type of immune response in LRTI-affected human lungs, our experimental data suggest that virus-induced alveolar establishment of MCs in combination with allergen exposure in the distal lung may evoke a long-lasting immune alteration since MCs are long lived and are likely to remain in the tissue well after the infection has been cleared. Speculatively, LRTI-induced alveolar MC expansion early in life might therefore affect sensitisation and susceptibility towards allergens and asthma development later in life. 

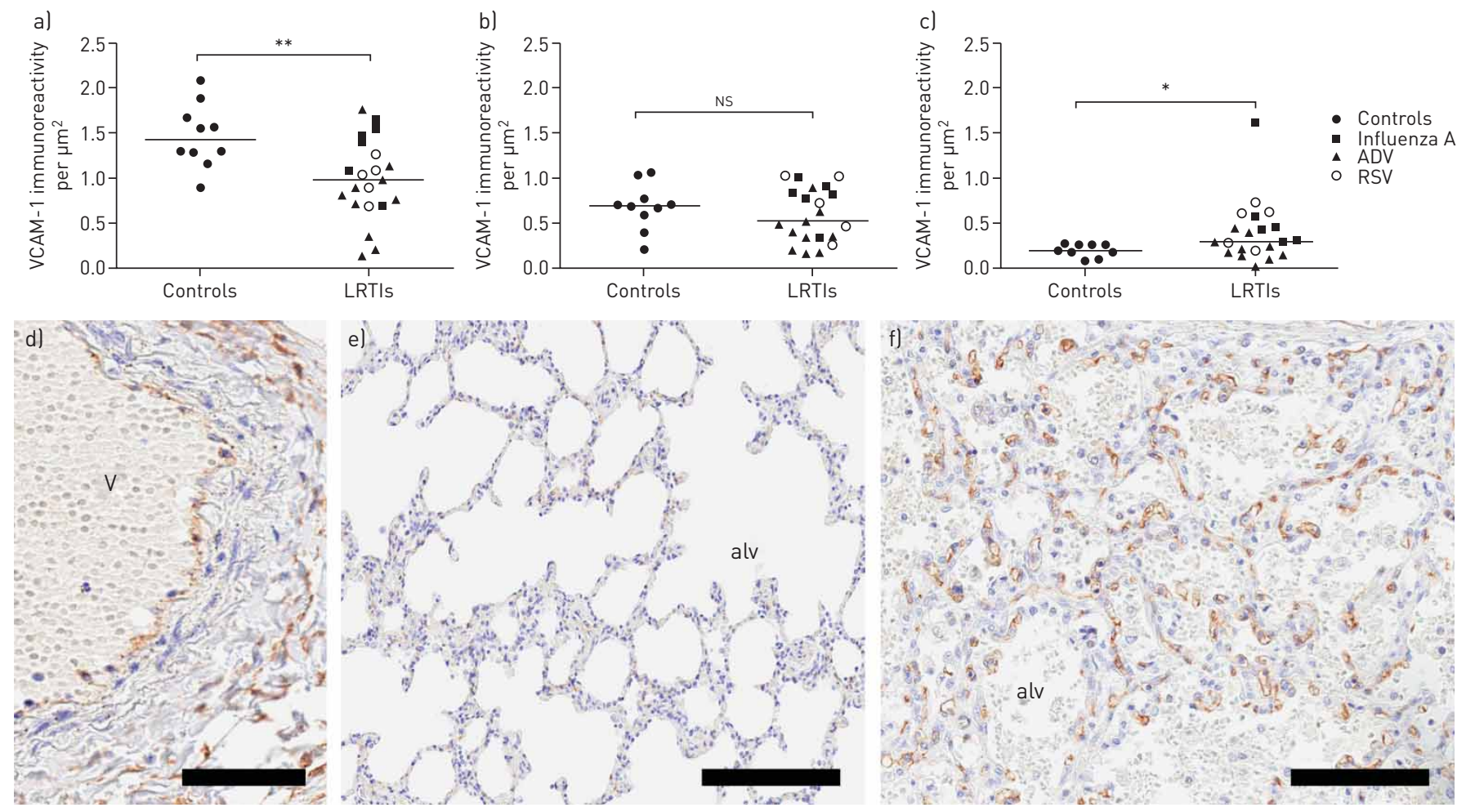

FIGURE 4 Vascular cell adhesion molecule (VCAM)-1 expression in a) small airway and b) pulmonary vessel walls, and c) alveolar parenchyma. d) Immunohistochemical staining of VCAM-1 in a pulmonary vessel from a child with lower respiratory tract infection (LRTI). VCAM-1 expression in alveolar parenchyma from el a control child and f) a child with LRTI, respectively. Scale bars: d) $50 \mu \mathrm{m}$; el $200 \mu \mathrm{m}$; f) $100 \mu \mathrm{m}$. Results were considered significant at $\mathrm{p} \leqslant 0.05$. NS: not significant; ADV: adenovirus; RSV: respiratory syncytial virus; V: vessel; alv: alveolus. *: $p \leqslant 0.05$ using Mann-Whitney rank sum test, in comparison to controls; ${ }^{* *}: p \leqslant 0.01$ using Mann-Whitney rank sum test, in comparison to controls.

Many studies have suggested a connection between early-in-life viral infections, especially in the lower airways, and subsequent development of asthma. Children who are affected by viral LRTI during sensitisation by aeroallergens have up to a 30 -fold increased risk of developing persistent or severe asthma, particularly when the events take place during postnatal lung growth [24]. The risk is affected by both intensity and frequency of the viral infection as well as allergen-specific IgE levels [25, 26]. The potential link between LRTI and asthma is further underscored by the fact that robust alveolar MC changes seem to be common features of adult asthma [18, 19, 27].

A main finding in our study is that a resident alveolar MC population was virtually absent in the nondiseased lungs from young children. This is in stark contrast with the healthy human adult lung where the highest density of MCs is found in the alveolar parenchyma [7]. Likewise, laboratory mice do not have resident alveolar MCs. In rodents, it is believed that such a population does not emerge with age unless subjected to a viral insult to the lung [28]. Indeed, our study shows that a viral infection evokes a rapid establishment of an alveolar MC population in mice and children. If this occurs during infancy, which is a critical stage of lung and immune response development, this could theoretically lead to increased susceptibility for sensitisation and asthma development later in life. Although our animal study showed an increase in MC numbers with influenza A alone, the numbers further increased with a combination of influenza A and HDM at both day 36 and 57. This might indicate that the inflammatory milieu caused by a combination of virus and allergen further enhances homing and/or survival of MC into the affected tissue. Although the methods used in our study are unable to evaluate MC activation, our analysis implicates that young children who suffered from LRTIs and survived, and who have susceptibility towards allergic sensitisation, may have a higher predisposition to react with an elevated MC response upon activation.

Due to their strategic position at mucosal surfaces MCs are among the first cell types to encounter foreign agents. As a consequence of this, MCs have been proposed to have important roles in the defence against pathogens [29-31]. Both in vivo and in vitro studies have demonstrated that MCs express several receptors that facilitate cellular responses to pathogens, including CD48, complement receptors, Fc receptors and Toll-like receptors [32-35]. In a recent study, Graham et al. [36] showed that cultured murine MCs are 
activated during influenza infection. Whereas activation and de novo production of cytokines is regulated by RIG-I/MAVS-dependent mechanisms, their study showed that degranulation is independent of this signalling pathway, indicating highly controlled MC activation during viral infections in mice. It was also shown that mice lacking MCs develop less severe inflammatory response and lung damage to influenza A compared to their wild-type counterparts [36]. Higher RSV-specific IgE titres have been shown in nasopharyngeal secretions of wheezing young children compared to young children who do not wheeze upon RSV infection [37-39]. Thus, virus-specific IgE might activate MCs and other FceRI-expressing cells that results in the release of various pro-inflammatory mediators. Indeed, the nasopharyngeal concentration of the bronchoconstrictive $\mathrm{MC}$ mediator leukotriene $\mathrm{C}_{4}$ correlated with IgE titres in young children with RSV bronchiolitis [40]. Another evidence of infection-induced MC activation is that histamine levels are increased in patients during a virally induced asthma exacerbation [41]. An elevated MC response might therefore be part of the normal immune defence but the time point of infection, type of virus, or whether or not there is a simultaneous allergic sensitisation might predispose for asthma development. An expanded alveolar MC population in childhood, during a time-point of lung growth, is likely to have an impact on the development and remodelling of lung tissue as well as the immune responses and sensitisation towards harmful agents and allergens. Thus, establishment of an alveolar MC population early in life is likely to contribute to an aggravated inflammatory response against allergens or other pro-inflammatory agents that reach the distal lung [42, 43].

Migration of MCs to the airways has previously been shown in mouse models of allergic airway inflammation [44] and the increase in pulmonary MCs is preceded by a recruitment of MC progenitors from the blood into the lung [45]. For this recruitment to occur, MC progenitors need to express integrin $\alpha_{4} \beta_{1}$ and $\alpha_{4} \beta_{7}$, which interact with VCAM-1 on the lung endothelium [46]. In our study, we investigated whether the increase in lung MCs upon LRTI could result from recruitment of MC progenitors from the blood. We used CD34 in combination with tryptase to identify MC progenitors in the lung since tryptase is a MC specific marker and mature human MCs do not express CD34 [47, 48]. In young children infected with virus, this population of MC progenitors was increased within the alveolar parenchyma. It is likely that the frequency of MC progenitors is significantly underestimated using this combination of surface markers, as any MC progenitors that still have not developed tryptase-laden (i.e. $\mathrm{CD}_{3} 4^{+}$tryptase ${ }^{-}$ cells) will not be identified with this staining panel. Although few in numbers, the MC progenitors were found to be significantly increased in the alveolar parenchyma of young children affected by viral infections, which together with the increased VCAM-1 expression may well have resulted in the higher total MC density in the peripheral lung. This is supported by animal studies of influenza A infection in mice [28]. Importantly, BRIGHTLING et al. [49] showed that the number of tryptase ${ }^{+}$mast cells increased in the airway smooth muscle (ASM) in subjects with asthma compared with subjects with eosinophilic bronchitis and to that in normal controls. This group also showed that MCs within the ASM layer are linked to airway hyperresponsiveness [50]. Very few studies have investigated MCs in childhood asthma and some have found no difference in $\mathrm{MC}$ numbers in comparison to controls [51, 52]. An important study by LezMi et al. [53] showed that the number of submucosal MCs was higher in symptomatic childhood asthma than in the paucisymptomatic group. They concluded that MCs are associated with severe exacerbations and submucosal eosinophilic inflammation in children with severe asthma, which suggests an important role for MCs in the development of asthmatic symptoms.

A study by AL-Garawi et al. [54] showed that infant mice are, unlike adult mice, hyporesponsive to HDM exposure. The hyporesponsiveness is, however, overcome in mice previously infected with influenza A infection. Furthermore, the pathological tissue changes persist into adulthood and are associated with reduced lung function. These findings correlate well to the alternations in MCs that we describe here. In the present study, we used tissue from the same experimental study [54] and found an increased number of alveolar MCs in influenza A and influenza A+HDM challenged mice, but not in mice exposed to HDM alone. The increase was significant in infected infant mice after 36 days but further elevated when combined with an allergic inflammation caused by HDM. The increase was still present after 57 days even though mice had been allowed to recover for 3 weeks and acute inflammation had subsided. At day 57, there were still patchy areas of remodelled lung architecture with MCs remaining in the influenza A+HDM mice. Our data indicate that the increased number of MCs persists well after the infection has cleared. This might give a predisposition to react to allergens, viruses and other MC stimuli in the future, and lead to asthma development later in life. However, it should be noted that the murine model used may not be equivalent to processes happening in the human lung, and that it is difficult to make this link without more human data. Although not in the scope of this study, it would be of great interest to explore the long-term presence of alveolar MCs even after the alveolar architecture has returned to the pre-infected state. Based on our result that only influenza A+HDM-treated mice had an increased MC population, one might speculate that the combination of HDM and influenza A causes the requirement for a maintained altered parenchymal architecture, which thereby supports MC survival and localisation. 
In conclusion, by studying a unique human tissue material from young children who have died from LRTIs, we show here that distal viral infections cause a rapid de novo increase in MC populations in the alveolar parenchyma. The recruited MCs are likely to have important roles in the host defence against viruses. Our animal data further indicate that infection with influenza A and concomitant allergen exposure lead to abnormally elevated accumulation of MCs that persists into adulthood. Hence, LRTIs seem to represent an important mechanism of establishing a long-lasting presence of alveolar MCs, a population that is dramatically altered in adult asthma $[12,13]$. Thus, children who suffer from a distal respiratory viral infection and survive are likely to have an increased resident alveolar MC population already in younger years, which speculatively affect their susceptibility to allergen sensitisation and development of asthma. Further research regarding the role of alveolar MCs in viral infection and the connection to asthma development under human in vivo conditions is warranted.

Acknowledgements: Special thanks to Anette Debertin and Thomas Tschernig (Hannover Medical School, Hannover, Germany) who performed the autopsies of the control children. We thank Karin Jansner and Britt-Marie Nilsson (Unit of Airway Inflammation, Lund University, Lund, Sweden) for skilful technical assistance with tissue processing and immunohistochemical staining. We also thank Göran Eriksson (Dept of Respiratory Medicine and Allergology, Lund University, Lund, Sweden) for reading and providing helpful comments on the manuscript.

Conflict of interest: C.K. Andersson has nothing to disclose. M. Shikhagaie has nothing to disclose. M. Mori has nothing to disclose. A. Al-Garawi has nothing to disclose. J.L. Reed has nothing to disclose. A.A. Humbles is an employee of and holds shares in MedImmune LLC. R. Welliver has nothing to disclose. T. Mauad has nothing to disclose. L. Bjermer has nothing to disclose. M. Jordana has nothing to disclose. J.S. Erjefält has nothing to disclose.

Support statement: This study was supported by the Heart and Lung Foundation, Sweden; the Swedish Medical Research Council; the Swedish Asthma and Allergy Association Research Foundation; and The Crafoord Foundation. Funding information for this article has been deposited with the Crossref Funder Registry.

\section{References}

$1 \quad$ Martinez FD. Viral infections and the development of asthma. Am J Respir Crit Care Med 1995; 151: 1644-1647.

2 Pavia AT. Viral infections of the lower respiratory tract: old viruses, new viruses, and the role of diagnosis. Clin Infect Dis 2011; 52: Suppl. 4, S284-S289.

3 Holt PG, Sly PD. Interaction between adaptive and innate immune pathways in the pathogenesis of atopic asthma: operation of a lung/bone marrow axis. Chest 2011; 139: 1165-1171.

4 Mackenzie KJ, Anderton SM, Schwarze J. Viral respiratory tract infections and asthma in early life: cause and effect? Clin Exp Allergy 2014; 44: 9-19.

5 Jackson DJ, Lemanske RF Jr. The role of respiratory virus infections in childhood asthma inception. Immunol Allergy Clin North Am 2010; 30: 513-522.

6 Sigurs N, Gustafsson PM, Bjarnason R, et al. Severe respiratory syncytial virus bronchiolitis in infancy and asthma and allergy at age 13. Am J Respir Crit Care Med 2005; 171: 137-141.

7 Andersson CK, Mori M, Bjermer L, et al. Novel site-specific mast cell subpopulations in the human lung. Thorax 2009; 64: 297-305.

8 Dawicki W, Marshall JS. New and emerging roles for mast cells in host defence. Curr Opin Immunol 2007; 19: 31-38.

9 Malaviya R, Ikeda T, Ross E, et al. Mast cell modulation of neutrophil influx and bacterial clearance at sites of infection through TNF-alpha. Nature 1996; 381: 77-80.

10 Echtenacher B, Mannel DN, Hultner L. Critical protective role of mast cells in a model of acute septic peritonitis Nature 1996; 381: 75-77.

11 Castleman WL, Sorkness RL, Lemanske RF Jr, et al. Viral bronchiolitis during early life induces increased numbers of bronchiolar mast cells and airway hyperresponsiveness. Am J Pathol 1990; 137: 821-831.

12 Gelfand EW, Kraft M. The importance and features of the distal airways in children and adults. J Allergy Clin Immunol 2009; 124: Suppl., S84-S87.

13 Sutherland ER, Martin RJ, Bowler RP, et al. Physiologic correlates of distal lung inflammation in asthma. J Allergy Clin Immunol 2004; 113: 1046-1050.

14 Bergqvist A, Andersson CK, Mori M, et al. Alveolar T-helper type-2 immunity in atopic asthma is associated with poor clinical control. Clin Sci 2015; 128: 47-56.

15 Balzar S, Chu HW, Strand M, et al. Relationship of small airway chymase-positive mast cells and lung function in severe asthma. Am J Respir Crit Care Med 2005; 171: 431-439.

16 Kraft M, Djukanovic R, Wilson S, et al. Alveolar tissue inflammation in asthma. Am J Respir Crit Care Med 1996; 154: $1505-1510$

17 Wenzel SE. Asthma: defining of the persistent adult phenotypes. Lancet 2006; 368: 804-813.

18 Andersson CK, Bergqvist A, Mori M, et al. Mast cell-associated alveolar inflammation in patients with atopic uncontrolled asthma. J Allergy Clin Immunol 2011; 127: 905-912.

19 Andersson CK, Tufvesson E, Aronsson D, et al. Alveolar mast cells shift to an FceRI-expressing phenotype in mild atopic asthma: a novel feature in allergic asthma pathology. Allergy 2011; 66: 1590-1597.

20 Andersson CK, Mori M, Bjermer L, et al. Alterations in lung mast cell populations in patients with chronic obstructive pulmonary disease. Am J Respir Crit Care Med 2010; 181: 206-217.

21 Forssell J, Sideras P, Eriksson C, et al. Interleukin-2-inducible T cell kinase regulates mast cell degranulation and acute allergic responses. Am J Respir Cell Mol Biol 2005; 32: 511-520.

22 Hallgren J, Gurish MF. Pathways of murine mast cell development and trafficking: tracking the roots and routes of the mast cell. Immunol Rev 2007; 217: 8-18. 
23 Gurish MF, Boyce JA. Mast cells: ontogeny, homing, and recruitment of a unique innate effector cell. $J$ Allergy Clin Immunol 2006; 117: 1285-1291.

24 Jackson DJ. The role of rhinovirus infections in the development of early childhood asthma. Curr Opin Allergy Clin Immunol 2010; 10: 133-138.

25 Holt PG, Rowe J, Kusel M, et al. Toward improved prediction of risk for atopy and asthma among preschoolers: a prospective cohort study. J Allergy Clin Immunol 2010; 125: 653-659.

26 Schwarze J, Hamelmann E, Bradley KL, et al. Respiratory syncytial virus infection results in airway hyperresponsiveness and enhanced airway sensitization to allergen. J Clin Invest 1997; 100: 226-233.

27 Balzar S, Strand M, Rhodes D, et al. IgE expression pattern in lung: relation to systemic IgE and asthma phenotypes. J Allergy Clin Immunol 2007; 119: 855-862.

28 Zarnegar B, Mendez-Enriquez E, Westin A, et al. Influenza infection in mice induces accumulation of lung mast cells through the recruitment and maturation of mast cell progenitors. Front Immunol 2017; 8: 310.

29 Joulia R, Gaudenzio N, Rodrigues $\mathrm{M}$, et al. Mast cells form antibody-dependent degranulatory synapse for dedicated secretion and defence. Nat Commun 2015; 6: 6174.

30 Cruse G, Fernandes VE, de Salort J, et al. Human lung mast cells mediate pneumococcal cell death in response to activation by pneumolysin. J Immunol 2010; 184: 7108-7115.

31 Dakhama A, Lee YM, Ohnishi $\mathrm{H}$, et al. Virus-specific IgE enhances airway responsiveness on reinfection with respiratory syncytial virus in newborn mice. J Allergy Clin Immunol 2009; 123: 138-145.

32 Shelburne CP, Abraham SN. The mast cell in innate and adaptive immunity. Adv Exp Med Biol 2011; 716: $162-185$

33 Dietrich N, Rohde M, Geffers R, et al. Mast cells elicit proinflammatory but not type I interferon responses upon activation of TLRs by bacteria. Proc Natl Acad Sci USA 2010; 107: 8748-8753.

34 Guhl S, Franke R, Schielke A, et al. Infection of in vivo differentiated human mast cells with hantaviruses. J Gen Virol 2010; 91: 1256-1261.

35 Burke SM, Issekutz TB, Mohan $\mathrm{K}$, et al. Human mast cell activation with virus-associated stimuli leads to the selective chemotaxis of natural killer cells by a CXCL8-dependent mechanism. Blood 2008; 111: 5467-5476.

36 Graham AC, Hilmer KM, Zickovich JM, et al. Inflammatory response of mast cells during influenza A virus infection is mediated by active infection and RIG-I signaling. J Immunol 2013; 190: 4676-4684.

37 Sung RY, Hui SH, Wong CK, et al. A comparison of cytokine responses in respiratory syncytial virus and influenza A infections in infants. Eur J Pediatr 2001; 160: 117-122.

38 Welliver RC, Duffy L. The relationship of RSV-specific immunoglobulin E antibody responses in infancy, recurrent wheezing, and pulmonary function at age 7-8 years. Pediatr Pulmonol 1993; 15: 19-27.

39 Welliver RC, Sun M, Rinaldo D, et al. Respiratory syncytial virus-specific IgE responses following infection: evidence for a predominantly mucosal response. Pediatr Res 1985; 19: 420-424.

40 Volovitz B, Welliver RC, De Castro G, et al. The release of leukotrienes in the respiratory tract during infection with respiratory syncytial virus: role in obstructive airway disease. Pediatr Res 1988; 24: 504-507.

41 Yamaya M. Virus infection-induced bronchial asthma exacerbation. Pulm Med 2012; 2012: 834826.

42 Custovic A, Woodcock H, Craven M, et al. Dust mite allergens are carried on not only large particles. Pediatr Allergy Immunol 1999; 10: 258-260.

43 Taylor PE, Flagan RC, Miguel AG, et al. Birch pollen rupture and the release of aerosols of respirable allergens. Clin Exp Allergy 2004; 34: 1591-1596.

44 Schmit D, Le DD, Heck S, et al. Allergic airway inflammation induces migration of mast cell populations into the mouse airway. Cell Tissue Res 2017; 369: 331-340.

45 Hallgren J, Jones TG, Abonia JP, et al. Pulmonary CXCR2 regulates VCAM-1 and antigen-induced recruitment of mast cell progenitors. Proc Natl Acad Sci USA 2007; 104: 20478-20483.

46 Abonia JP, Hallgren J, Jones T, et al. Alpha-4 integrins and VCAM-1, but not MAdCAM-1, are essential for recruitment of mast cell progenitors to the inflamed lung. Blood 2006; 108: 1588-1594.

47 Drew E, Huettner CS, Tenen DG, et al. CD34 expression by mast cells: of mice and men. Blood 2005; 106 $1885-1887$.

48 Welker P, Grabbe J, Zuberbier T, et al. Mast cell and myeloid marker expression during early in vitro mast cell differentiation from human peripheral blood mononuclear cells. J Invest Dermatol 2000; 114: 44-50.

49 Brightling CE, Bradding P, Symon FA, et al. Mast-cell infiltration of airway smooth muscle in asthma. $N$ Engl Med 2002; 346: 1699-1705.

50 Siddiqui S, Mistry V, Doe C, et al. Airway hyperresponsiveness is dissociated from airway wall structural remodeling. J Allergy Clin Immunol 2008; 122: 335-341.

51 Bossley CJ, Fleming L, Gupta A, et al. Pediatric severe asthma is characterized by eosinophilia and remodeling without $\mathrm{T}_{\mathrm{H}} 2$ cytokines. J Allergy Clin Immunol 2012; 129: 974-982.

52 O'Reilly R, Ullmann N, Irving S, et al. Increased airway smooth muscle in preschool wheezers who have asthma at school age. J Allergy Clin Immunol 2013; 131: 1024-1032.

53 Lezmi G, Galmiche-Rolland L, Rioux S, et al. Mast cells are associated with exacerbations and eosinophilia in children with severe asthma. Eur Respir J 2016; 48: 1320-1328.

54 Al-Garawi A, Fattouh R, Botelho F, et al. Influenza A facilitates sensitization to house dust mite in infant mice leading to an asthma phenotype in adulthood. Mucosal Immunol 2011; 4: 682-694. 